\title{
Successful implementation of thirty five major orthopaedic procedures under poor conditions after the two thousand and fifteen Nepal earthquake
}

\author{
Wei Zheng ${ }^{1}$ (D) $\cdot$ Yonghe $\mathrm{Hu}^{1} \cdot$ Hai Xin ${ }^{1}$
}

Received: 11 April 2016 / Accepted: 23 August 2016/Published online: 2 September 2016

(C) The Author(s) 2016. This article is published with open access at Springerlink.com

\begin{abstract}
Background After receiving the 25 April 2015 Nepal earthquake relief mission, a fully self-sufficient Rescue Center of Trauma set up quickly in downtown Kathmandu by Chengdu Military Medical Team of PLA P. R. China.

Methods The medical team consisted of 68 members and 40 tons of supplies, which was equivalent to a small hospital. The medical area and living area were constructed with tents. Operating areas were converted from eight simple bungalows. The main purpose of the Rescue Center of Trauma was to save those earthquake survivors who needed surgery.

Results From 30 April to 10 May, 35 cases of orthopaedic internal fixation and external fixation operations were completed in the Rescue Center of Trauma. Surgery involved a total of 27 patients. All of the 27 orthopaedic surgery patients received treatment without any serious complications, including internal fixation failure, infection, amputation, limb deformities, limb dysfunction, or skin necrosis.

Conclusions Trauma infection rates are usually higher after an earthquake. Due to poor conditions, implementation of orthopaedic surgery at a field hospital is limited due to a lack of blood, equipment, and drugs. Infection control remains a key determinant of the success of surgery. Effective measures to control infection include strict environmental disinfection, extending the sterilizing time of fixation devices and supplies,
\end{abstract}

Electronic supplementary material The online version of this article (doi:10.1007/s00264-016-3284-2) contains supplementary material, which is available to authorized users.

Wei Zheng

zw770880@126.com

1 Chengdu Military General Hospital, Chengdu, China doubling the number and time of washing and disinfection, and rational use of antibiotics based on past experience.

Keywords Field hospital $\cdot 2015$ Nepal earthquake · Orthopaedic surgery $\cdot$ Poor conditions $\cdot$ Rescue center of trauma

\section{Introduction}

The 2015 Nepal earthquake (also known as the Gorkha earthquake) occurred at 11:56 Nepal Standard Time on 25 April, with a magnitude of $7.8 \mathrm{M}_{\mathrm{w}}$ or $8.1 \mathrm{M}_{\mathrm{s}}$ and a maximum Mercalli Intensity of IX [1, 2]. The earthquake and its aftershocks killed more than 8800 in Nepal and injured nearly three times as many [3]. After receiving the disaster relief mission, a fully self-sufficient medical team quickly set up, called the Chengdu Military Medical Team of PLA. The medical team had a total of 68 members, including medical personnel, disinfection and epidemic prevention personnel, liaison personnel, and logistics personnel, carrying more than 40 tons of medical and living supplies. On the morning of 27 April, two transport aircraft carrying the entire medical team arrived in Kathmandu. On an open space in Singadurbar, downtown Kathmandu, the medical team built a temporary hospital two days after arrival, named Rescue Center of Trauma PLA P. R. China. The center had one operating room (two operation beds), 30 beds and 16 care beds. The main purpose of the centre was to save those earthquake survivors who needed surgery. From the first surgery on 30 April to the team's departure from Nepal on 15 May, a total of 267 patients received treatment, in which 132 patients received debridement, 71 patients were hospitalized, and 27 patients (35 fractures) underwent orthopaedic surgery. None of the operations had significant complications such as internal fixation failure, infection, 


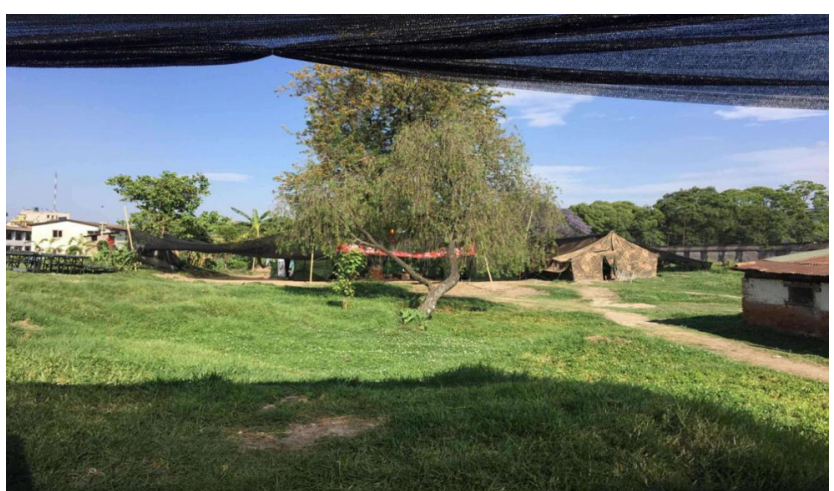

Fig. 1 Location: a wasteland in Singadurbar area, nearby the Lion's Palace

amputation, limb deformities, limb dysfunction, skin necrosis or death. According to the official news, our medical team was the only foreign rescue team that could carry out orthopaedic surgery independently after the earthquake in Nepal.

\section{Materials and methods}

\section{Location}

Nepal Ministry of Defence provided three places for the final selection. The medical team selected a wasteland in Singadurbar area, nearby the Lion's Palace. The place was located in the Kathmandu city centre, which had convenient transportation, electricity, and water supply. It was large and open, reducing the potential destruction of aftershocks (Fig. 1). The medical area and living area were constructed with tents (Fig. 2). Operating areas were converted from eight simple bungalows (Figs. 3, 4 and 5).

\section{Personnel structure and medical equipment}

The team consisted of 68 members (Fig. 6), and 40 tons of supplies. It was completely self-sufficient, equivalent to a small hospital. The medical team could accept trauma, fracture, traumatic brain injury, ENT, and obstetrics patients.

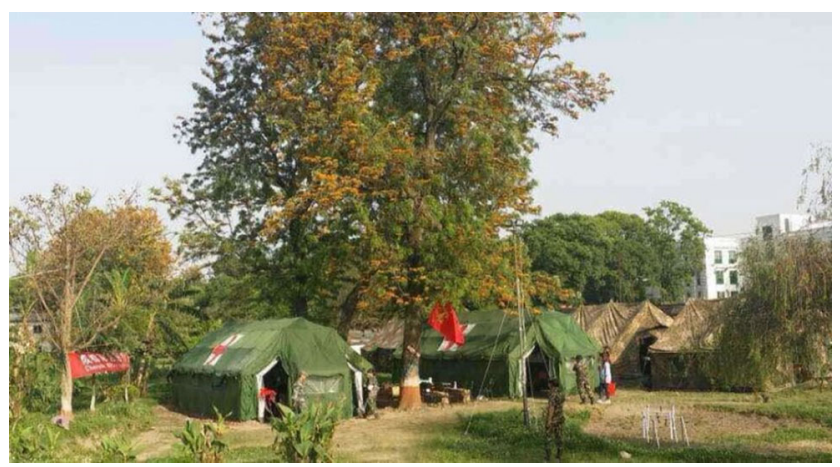

Fig. 2 Rescue Center of Trauma: Medical area and living area

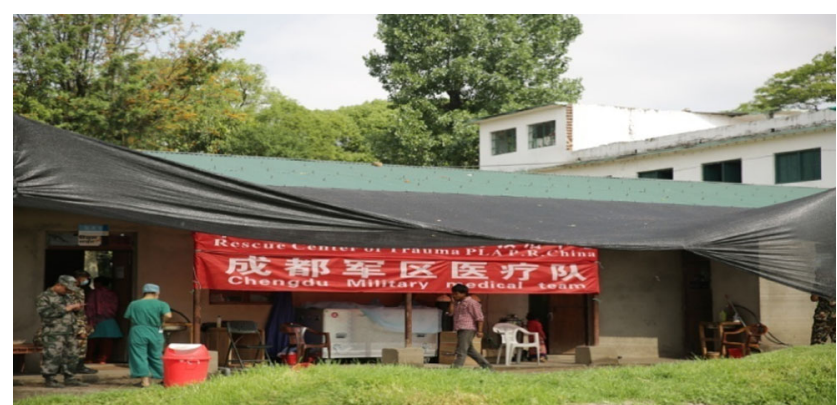

Fig. 3 Eight simple bungalows were converted into operation rooms, including the operation room, the preparation room, the disinfection room, the X-ray examination room, and the post-operative recovery room

Emergency and observing areas were equipped with multifunction ECG, oxygen machines, defibrillators, ECG, and suction devices. The operation room was equipped with two anesthesia machines, two monitors, two oxygen machines, two operation beds, and other related equipment. It was capable of completing general anesthesia surgery. The medical technology group consisted of ultrasound, radiology, and laboratory doctors, equipped with a portable X-ray machine, three portable ultrasound machines, two automatic biochemical analyzers, and two blood analyzers.

\section{Disinfection and epidemic prevention}

First, the team weeded the entire area, drove out the mice, and killed mosquitoes. For disinfection, we used $250 \mathrm{mg} / \mathrm{L}$ available chlorine content of Sodium dichloroisocyanurate aerosol spray in the environment and the operation room (daily amount of $30 \mathrm{ml} / \mathrm{m}^{3}$ ).

\section{Pre-operative preparation}

\section{Patient examination}

All patients received a full set of haematology tests, including routine blood tests, liver function, kidney function, blood coagulation, and infectious diseases. Other tests also include electrocardiogram, abdominal ultrasonography, and X-ray examination.

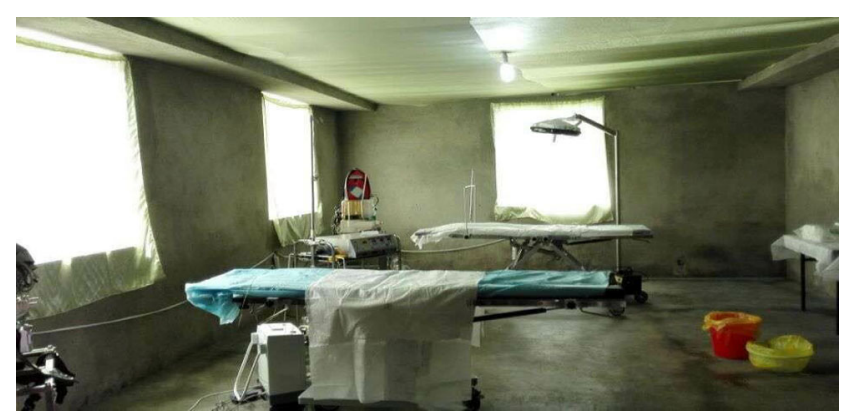

Fig. 4 Operation room, in which two operations can be carried out at the same time 


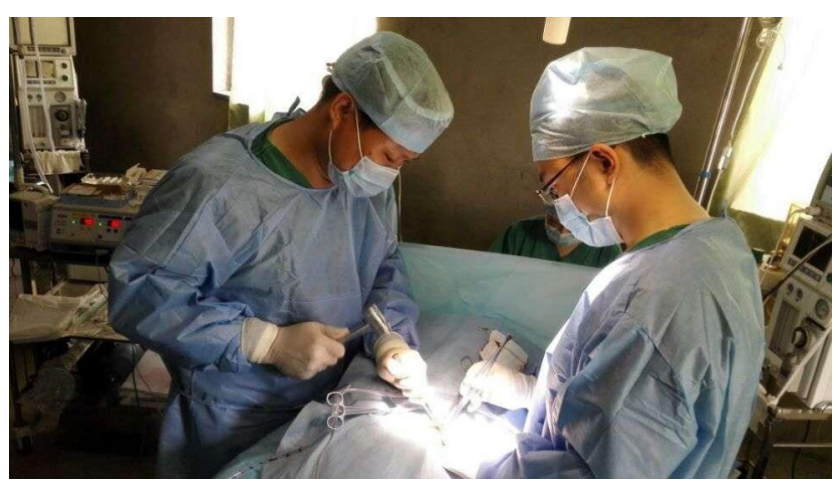

Fig. 5 The medical team performing the surgical procedure

\section{Sterilization of internal fixations, external fixations, and surgical instruments}

A high-pressure steam sterilizer was used, controlling steam pressure $105 \sim 140 \mathrm{KPa}$, temperature $121 \sim 126{ }^{\circ} \mathrm{C}(249.8 \sim 258.8 \mathrm{~F})$, for 45 minutes.

\section{Pre-operative prophylactic antibiotics}

Closed fracture patients received intravenous infusion of $1 \mathrm{~g}$ of cefazol half an hour before surgery. Patients in poor condition or with infected wounds received intravenous infusion of $1-2 \mathrm{~g}$ of ceftriaxone two hours before surgery.

\section{Results}

The best period for orthopedic surgery was within one week after the earthquake $[4,5]$. In the Rescue Center of Trauma, as soon as the patients completed preoperative examination, the surgeons could immediately begin surgery.

From 30 April to 10 May, 35 cases of orthopedic internal fixation and external fixation surgeries were completed in the centre. Surgeries involved a total of 27 patients, including 13 men and 14 women. There were 20 patients with only one fracture; two women and one man accepted operation with two parts of the fracture at the same time; three women received two surgeries at different times; and one woman received three fracture surgeries (Table 1). When the centre was closed, all of the 27 orthopaedic surgery patients had no major complications of infection, amputation or death.

Patients were an average age of 48 years old, ranging from 12 to 86 years of age (Table 2). The older patients had relatively severe injuries. From the distribution of the fracture site, lower limb fractures were significantly more common than the upper limb fractures. The largest number of fractures was the fracture of tibia and fibula (Table 3). We finished 31 cases of open reduction and internal fixation incision (ORIF, 88.6\%), including four consolidation iliac bone grafting, one merger coracoclavicular ligament reconstruction, and one merger tendon repair surgery (Table 4). We completed four cases (11.4\%) of open reduction and external fixation (OREF), including a 25 -year-old female who underwent surgery twice at the same site (Fig. 7). Because of the limitations of the implantable devices and materials, the fixed materials we used might not have been the most appropriate. With no artificial material, we could only take the patient's iliac bone graft, so some of the patients' operation times were prolonged. To prevent infection, we increased the times of wound washes during surgery, which also increased the operation time.

The oldest patients in the center were two 86-yearold males. One man admitted on 1 May, had been

Fig. 6 Personnel structure

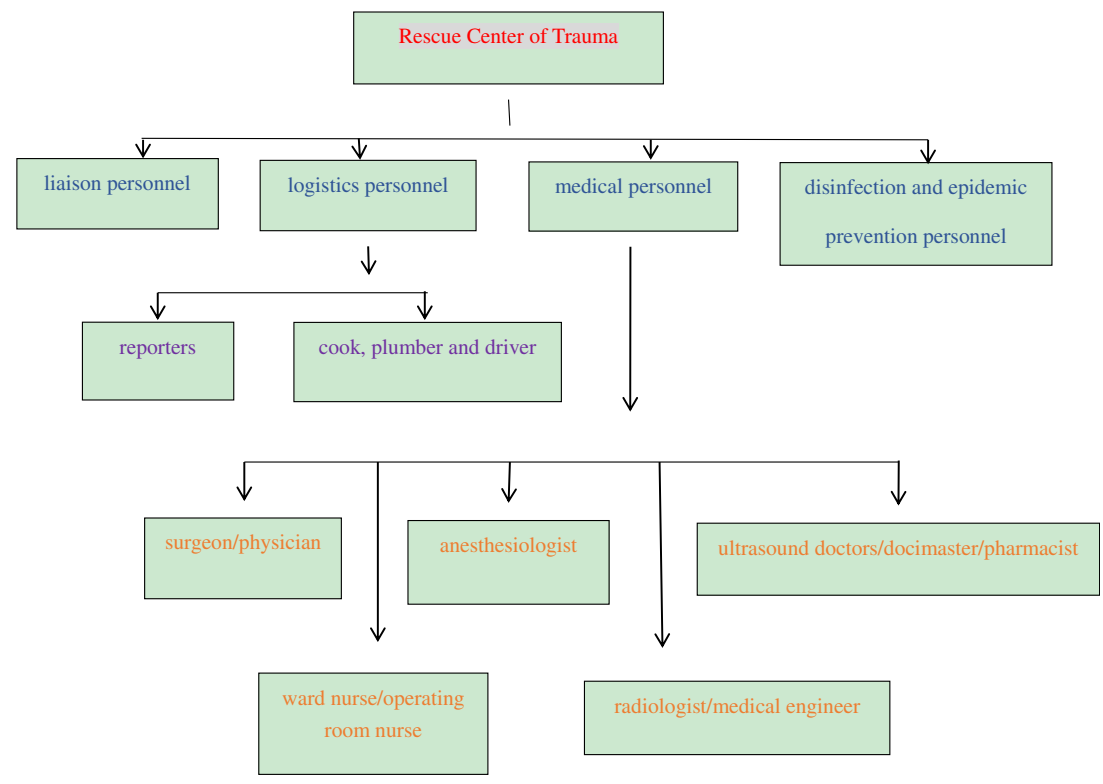


Table 1 Description of patient's basic situation and surgical record

\begin{tabular}{|c|c|c|c|c|c|c|}
\hline No. & Sex & Age & Diagnosis & Treatment & $\begin{array}{l}\text { Duration of } \\
\text { surgery (min) }\end{array}$ & Anesthesia \\
\hline 1 & M & 38 & $\begin{array}{l}\text { Second metatarsal fracture and dislocation of the } \\
\text { right foot }\end{array}$ & ORIF & 70 & EA \\
\hline 2 & M & 16 & Right femur fracture & ORIF & 85 & EA \\
\hline 3 & M & 70 & Left shoulder humerus fracture & ORIF & 40 & $\mathrm{BPBA}+\mathrm{CPBA}$ \\
\hline 4 & $\mathrm{~F}$ & 12 & Right femur fracture & ORIF & 130 & EA \\
\hline 5 & M & 52 & Left lower tibia and fibula fracture & ORIF & 120 & EA \\
\hline 6 & M & 86 & Open fractures of the right tibia and fibula & OREF & 145 & EA \\
\hline 7 & $\mathrm{~F}$ & 36 & Right tibia and fibula fracture (Pilon fracture) & ORIF + Iliac bone graft & 200 & EA \\
\hline 8 & M & 71 & Right clavicle fracture & ORIF & 145 & CPBA \\
\hline 9 & M & 31 & Left tibia and fibula fracture & ORIF & 90 & CSEA \\
\hline 10 & M & 24 & Right femur fracture & ORIF & 195 & CSEA \\
\hline 11 & M & 80 & Right radial multiple fractures & ORIF & 90 & BPBA \\
\hline 12 & M & 86 & Left trimalleolar fracture & ORIF & 285 & CSEA \\
\hline 13 & M & 80 & Left 2 nd and 4th metatarsal fracture & ORIF & 135 & CSEA \\
\hline 14 & $\mathrm{~F}$ & 17 & Right clavicle fracture & ORIF & 110 & GA \\
\hline 15 & $\mathrm{~F}$ & 21 & Scaphoid fracture dislocation of the right foot & ORIF & 65 & EA \\
\hline 16 & $\mathrm{~F}$ & 60 & Right clavicle fracture & ORIF & 55 & CPBA \\
\hline 17 & $\mathrm{~F}$ & 29 & $\begin{array}{l}\text { Right clavicle fracture with acromioclavicular } \\
\text { dislocation }\end{array}$ & $\begin{array}{l}\text { ORIF + reconstruction of coraco- } \\
\text { clavicular ligament }\end{array}$ & 105 & GA \\
\hline 18 & $\mathrm{~F}$ & 70 & left 2nd, 3rd, 4th, 5th metatarsal fractures & ORIF & 55 & CSEA \\
\hline 19 & M & 49 & Left calcaneal fractures & ORIF + Iliac bone graft & 310 & CSEA \\
\hline 20 & $\mathrm{~F}$ & 42 & Left calcaneal fractures & ORIF + Iliac bone graft & 175 & CSEA \\
\hline 21 & $\mathrm{~F}$ & 56 & Right femur fracture + Right foot first toe fracture & ORIF & 190 & GA \\
\hline 22 & M & 56 & Left humerus fracture + Left clavicle fracture & ORIF & 155 & $\mathrm{BPBA}+\mathrm{CPBA}$ \\
\hline 23 & $\mathrm{~F}$ & 16 & $\begin{array}{l}\text { Right ankle fracture + Right foot first toe injury } \\
\text { ruined }\end{array}$ & ORIF & 260 & EA \\
\hline \multirow[t]{2}{*}{24} & $\mathrm{~F}$ & 25 & Open fractures of the right tibia and fibula & OREF & 180 & EA \\
\hline & & & Open fractures of the right tibia and fibula & OREF (adjust again) & 135 & GA \\
\hline \multirow[t]{2}{*}{25} & $\mathrm{~F}$ & 60 & Right epicondyle of the humerus fracture & ORIF + Repair of tendon & 145 & BPBA \\
\hline & & & Right tibia and fibula fracture (Pilon fracture) & ORIF & 300 & CSEA \\
\hline \multirow[t]{2}{*}{26} & $\mathrm{~F}$ & 60 & Left radius and ulna fracture & ORIF + Iliac bone graft & 150 & GA \\
\hline & & & Left 3rd metacarpal fracture & ORIF & 40 & BPBA \\
\hline \multirow[t]{2}{*}{27} & $\mathrm{~F}$ & 65 & Right femur fracture + Right tibia and fibula fracture & ORIF & 300 & GA \\
\hline & & & Open fractures of left tibia and fibula & OREF & 80 & SA \\
\hline
\end{tabular}

ORIF: open reduction and internal fixation, OREF: open reduction and external fixation, EA: epidural anesthesia, BPBA: Brachial plexus block anesthesia

CPBA: cervical plexus block anesthesia, GA: general anesthesia, CSEA: combined spinal epidural anesthesia, SA: spinal anesthesia

No.21-23 patients underwent two orthopedics operations at the same time, respectively

No.24-26 patients underwent two orthopedics operations in two different dates, respectively

No.27 patient underwent three orthopedics operations in two different dates

outside the hospital for a simple dressing. He was diagnosed with right tibia and fibula open fractures. In that evening, the patient underwent right leg debridement, open reduction, and external fixation. The surgery lasted 145 minutes (Fig. 8). Before 4 May, the other 86-yearold man came to the center, a simple traumatic wound treatment had been done in another medical institution. The final diagnosis was left trimalleolar fracture. On 5
May, the patient underwent open reduction and internal fixation surgery. The surgery lasted 285 minutes, blood loss $200 \mathrm{ml}$ (Fig. 9).

As of 15 May the center closed, seven patients were discharged, and 20 patients were transferred to the government hospital of Nepal. They would later be transferred to a local hospital for rehabilitation. We worked with local doctors to complete the handover, including patient records, follow-up 
Table 2 Characteristics of 27 patients

\begin{tabular}{ll} 
Sex & \\
Men & 13 \\
Women & 14 \\
Age, $y$ & \\
Mean \pm SD & $48.4 \pm 23.1$ \\
Range & $12-86$ \\
No. of injured fracture site & \\
1 & 20 \\
2 & 6 \\
3 & 1 \\
\hline
\end{tabular}

treatment programs, and left them some orthopaedic instruments.

\section{Discussion}

In recent years, our medical team has participated several times in Chinese earthquake emergency medical rescues. These several large earthquakes were the 2008 Wenchuan earthquake, 2010 Yushu earthquake, 2012 Yunnan earthquake, and 2013 Lushan earthquake. The Chengdu Military Medical Team was China's first large-scale military dispatch medical team to perform an overseas earthquake rescue mission. After the earthquake, Nepal's medical and health resources were seriously insufficient. The government could only provide a piece of land and eight simple bungalows for our medical team. This forced our team to carry our own necessary medical supplies and living materials all by ourselves. No clean water, no formal operating room, no source of blood, no back-up support, coupled with language, culture, lifestyle, and religious differences made us more cautious in the treatment process. In fact, because of the difference of characteristic scenarios and injury patterns, the medical team needed to be flexible. Collaboration with other

Table 3 Distribution of 35 fracture sites (27 patients)

\begin{tabular}{lll}
\hline Fracture site & No. of cases & Left/right \\
\hline Tibia and fibula fracture & 9 & $3 / 6$ \\
Femoral fractures & 5 & $0 / 5$ \\
Clavicle fracture & 5 & $1 / 4$ \\
Humeral fracture & 3 & $2 / 1$ \\
Metatarsal fracture & 3 & $2 / 1$ \\
Ulnar fracture & 2 & $1 / 1$ \\
Ankle fracture & 2 & $1 / 1$ \\
Calcaneal fracture & 2 & $2 / 0$ \\
Toe fracture & 2 & $0 / 2$ \\
Metacarpal fracture & 1 & $1 / 0$ \\
Scaphoid fracture & 1 & $0 / 1$ \\
\hline
\end{tabular}

Table 4 Treatment

\begin{tabular}{ll}
\hline Treatment & No. \\
\hline ORIF & 25 \\
OREF & 4 \\
ORIF + Iliac bone graft & 4 \\
ORIF + reconstruction of coraco-clavicular ligament & 1 \\
ORIF + Repair of tendon & 1 \\
\hline
\end{tabular}

ORIF: open reduction and internal fixation

OREF: open reduction and external fixation

medical teams and volunteers could greatly enhance treatment capabilities [6-9].

We spent a total of 18 days in Nepal. Responding to the requirements of the Nepalese government, our medical team built up a trauma centre. The main task was to provide surgical treatment for those fracture patients, and the secondary task was to go out to make medical rounds. In this report, we introduced some experiences of surgery in harsh conditions. Because there was no intra-operative X-ray equipment, no blood supply, we did not treat patients with spinal fractures. As the surgical sterile environment could not achieve higher standards, we did not carry out joint replacement surgery either. When admitted to the trauma centre, almost 27 patients had multiple injuries, some of them without treatment for more than 72 hours, and some of them had been treated in other hospitals but had concurrent infection. Most of the fractures involved articular surface fracture, so surgery was more difficult and had greater risks. Under normal circumstances, the surgical techniques and instruments of these fractures are very mature [10]. However, in the case of emergency field conditions, surgeons had to take into consideration how to control bleeding, how to prevent infection, and how to maximize the retention and restoration of the patient's function $[11,12]$.

\section{Renovated operation room and disinfection indoor and outdoor}

According to the criteria of the trauma operation area, eight simple bungalows were converted into the operation area, which allowed two operations to be carried out at the same time, including the operation room, the preparation room, the disinfection room, the X-ray examination room and the postoperative recovery room. For harsh environments outside the rooms, with grass and a drainage ditch nearby, we got rid of the grass, eliminated the mosquitoes, and repeatedly sterilized the air indoors and outdoors.

The operation room was fumigated twice every day, morning before the surgery, and night after the work. After each surgery, we air sprayed disinfectant and then went on to do the next operation. 
Fig. 7 One 25-year-old female underwent right leg debridement, open reduction, and external fixation (twice on May 2 and 8, respectively)
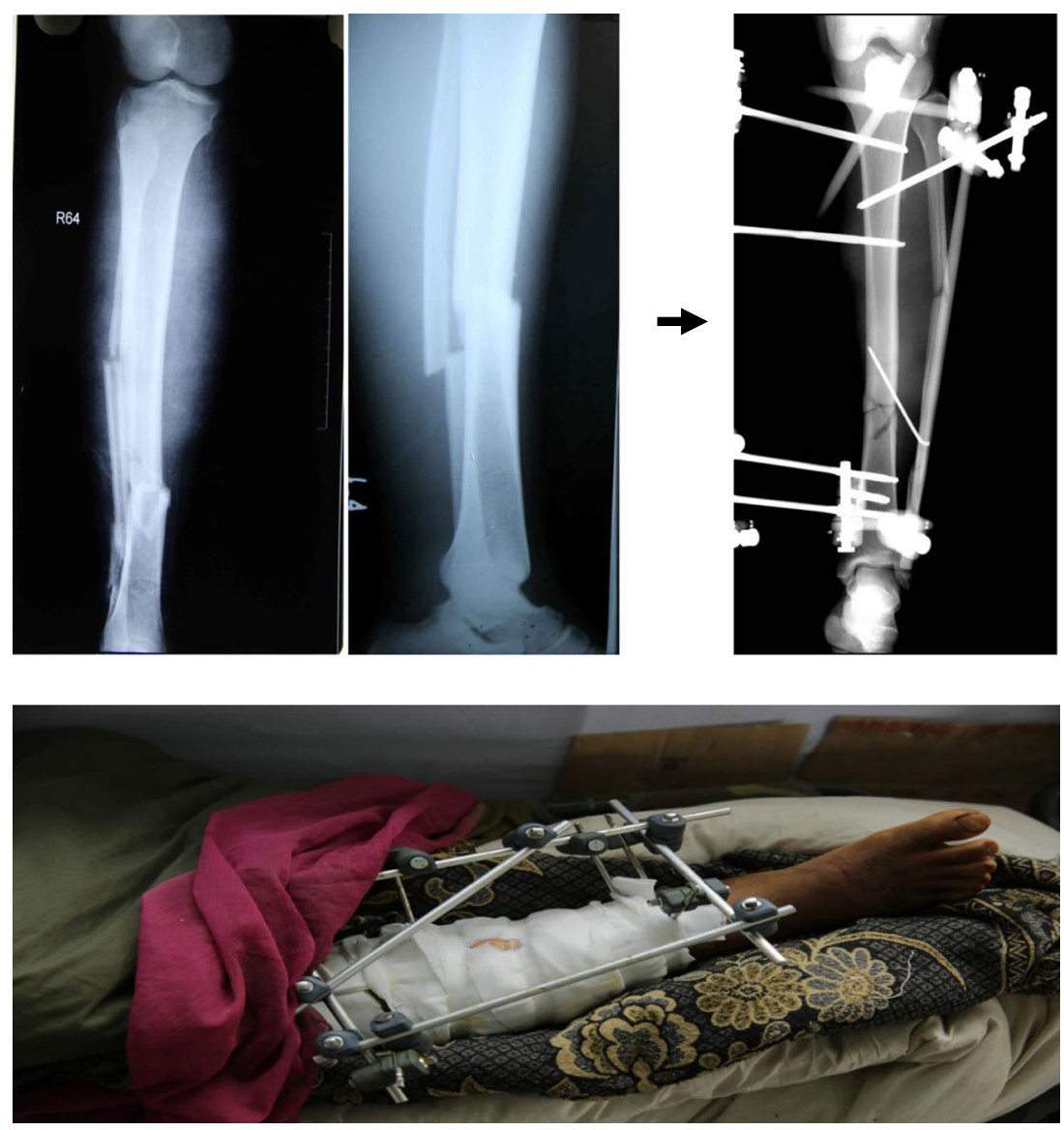

\section{Sterilization of internal/external fixation and the treatment of skin, and wounds}

The sterilizing time of fixation devices and supplies should be extended. Usually sterilization only takes 30 minutes to change the colour of the bar. We extended it to 45 minutes $\left(105 \sim 140 \mathrm{KPa}, 121 \sim 126{ }^{\circ} \mathrm{C}\right)$. Since the earthquake injured factors and local customs, many of the wounded had poor skin cleanliness. We paid great attention to pre-operative skin cleaning and doubled the amount of washing and disinfection during the operation. After surgery, we closely observed changes in the wounds, and increased the frequency of dressing change.

\section{Reduce blood loss}

Due to the shortage of blood sources, the surgery patients were faced with the risk of bleeding, death, and so on. We repeatedly discussed the surgical plan before the operation, and performed minimally invasive operations, used tourniquets, reduced intra-operative blood pressure [13], and expedited operating speed to reduce blood loss.

\section{Rational use of antibiotics based on past experience}

Unable to carry out bacterial culture and drug sensitivity tests, we could only refer to the past experience of earthquake survivors to guide drug treatment. In the 2008 Wenchuan earthquake, the majority of the survivors orthopaedic open wound infections were with Gram-negative bacteria. The top five pathogenic bacteria were Escherichia coli, Bowman acinetobacter, Staphylococcus aureus, Pseudomonas aeruginosa, and Enterobacter cloacae [14-17]. Most of the 2010 Yushu earthquake survivors were infected with Grampositive cocci, followed by Gram-negative bacteria, Grampositive bacteria, and fungi. A total of 12 species were found in Yushu earthquake survivors, including Staphylococcus, Enterococcus, Streptococcus, Escherichia, and Enterobacter spp [18]. Because of the possibility of superinfection [15], 26 patients after surgery received two antibiotics, including ceftriaxone and fosfomycin. Due to renal insufficiency, one patient used ceftriaxone only. Judging from the results of treatment, wound infection did not appear in any patients, proving the effect of antibiotics use. Under harsh conditions, in which bacterial culture and sensitivity tests may not be available or reliable, we believe that the use of broad-spectrum antibiotics, an increase in the amount of antibiotics, and combination therapy can do more good than harm. 
Fig. 8 One 86-year-old male underwent right leg debridement, open reduction, and external fixation
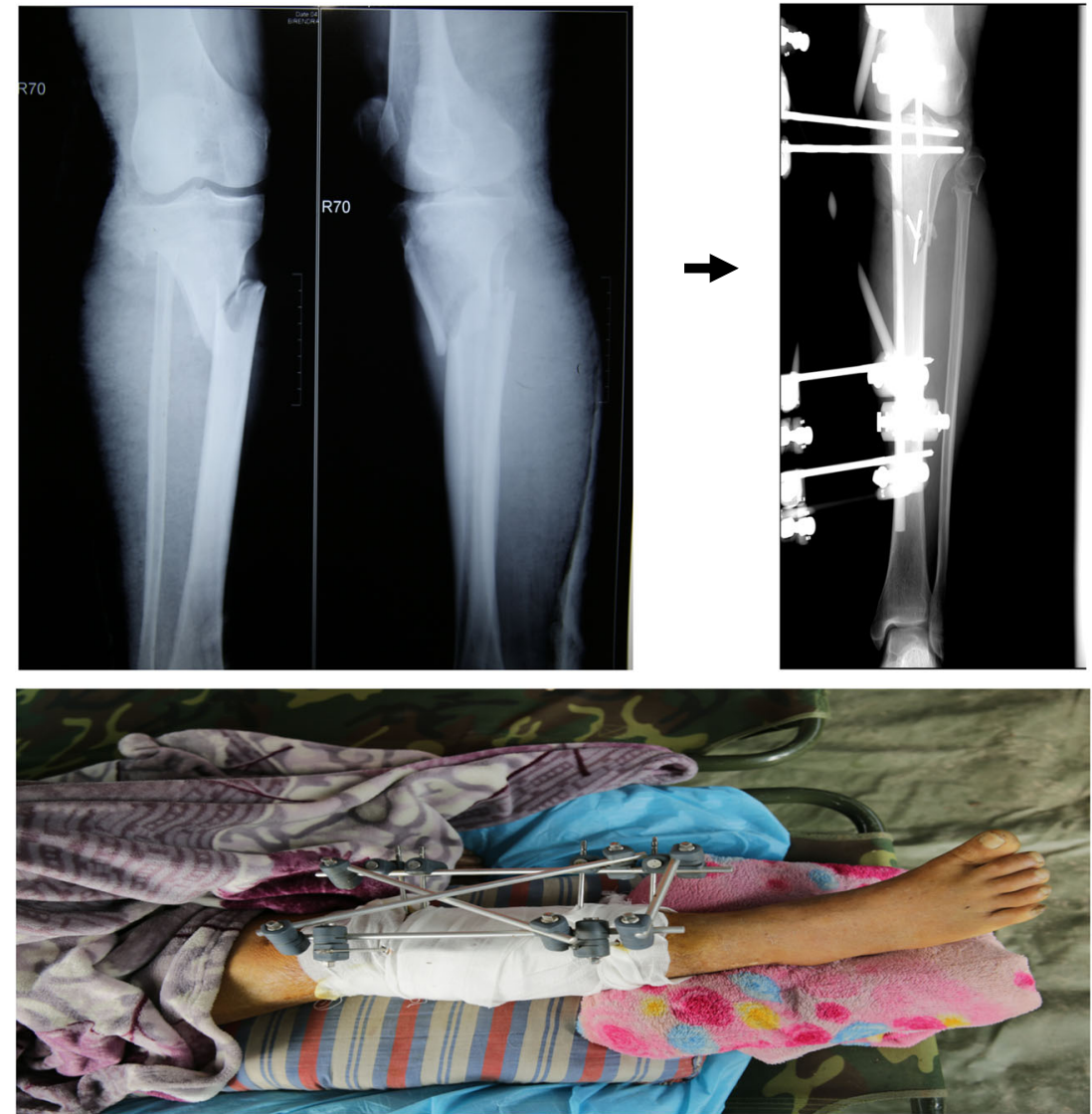

\section{Post-operative nutrition and food hygiene}

The patients' meals during hospitalization were provided by the government of Nepal. Because most patients were slim, the trauma centre gave each patient one additional egg everyday, in order to ensure protein supply and promote wound healing. We respect the local residents' living habits, but the trauma centre required all hospitalized patients in the hospital not to use hands to grab food. In order to prevent the occurrence of infectious diseases of the gastrointestinal tract, and reducing all possibilities that may affect post-operative recovery, they must use a spoon or fork instead of hands.

\section{The number of internal fixations and external fixations}

Four of the 35 operations were open reduction and external fixation procedures (OREF, $11.4 \%$ ), and 31 were open reduction and internal fixation surgery (ORIF, $88.6 \%$ ). Compared
Fig. 9 Another 86-year-old male underwent open reduction and internal fixation surgery of the left trimalleolar fracture
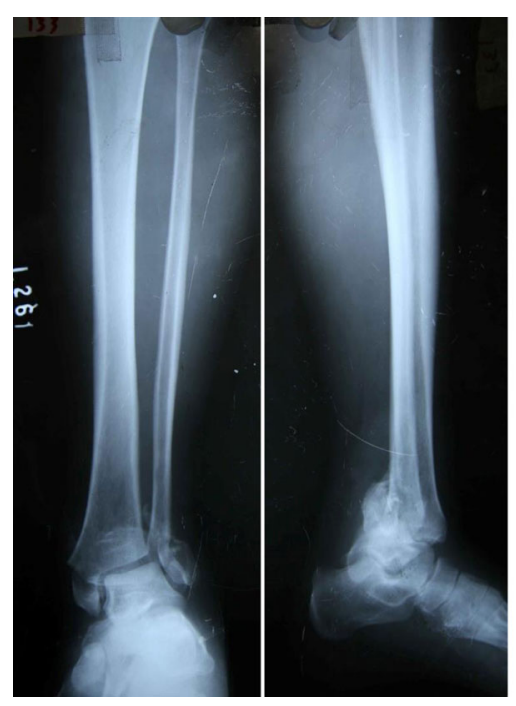
with past research, we found that the number of internal fixations in comparison with the external fixations was too high in this study. We propose three explanations for this.

First, our patients mainly came from the Nepalese army general hospital and other foreign medical teams. All of them were fracture patients and needed surgery. Most of the fractures were closed fractures.

Second, under the conditions of the earthquake, a considerable number of fractures were open fractures. Patients with open fractures are always associated with soft tissue injury and infection. These patients need to use external fixation support, and the sooner the better. Our trauma centre began receiving patients on the fourth day after the earthquake, and began to do surgery on the fifth day. Most of the surgeries were elective, and the number of emergency surgeries was low. According to a Nepalese liaison officer, most of the emergency surgery patients in need of external fixations had received treatment at the local hospital before our trauma centre opened. Due to the limited number of patients and bias, our study does not represent the epidemiological characteristics of earthquake injury.

Third, external fixation patients facing the possibility of secondary surgery were replaced with internal fixation. In the same circumstances, patients with external fixation recover more slowly than those patients with internal fixation, and require more post-operative care. In consideration of the local situation, we chose the internal fixation surgery for all of the patients with no wound infection.

\section{Effect of surgery and follow-up}

A short-time follow up cannot evaluate all the effects of internal fixation or whether other complications will occur. The progression from fracture reduction to functional recovery is a long process. If all goes well, this process will take six months to two years. In this process, each step will affect the final recovery. However, the most important step is the initial operation.

Unfortunately, our medical team was only able to stay for a limited time. We could not accompany all of the patients until they were fully recovered, or even stay until they were all discharged. Before we left Nepal, seven patients were discharged (length of stay: Range 8-13 days, Mean 9 days), and 20 patients were transferred to the government hospital. After surgery, all of the operative incisions healed well, and there was no skin necrosis. X-rays showed all of the reductions were satisfactory. So we think that the 35 cases of orthopedic surgery were a success.

Before leaving, we discussed every patient's treatment plan in detail with Nepalese army health officials, including removal of sutures, follow-up, functional exercise, and the second stage surgery.
By the time of this study, we learned from one Nepal army health official that none of the patients had serious complications, including internal fixation failure, infection, amputation, limb deformities, limb dysfunction, or skin necrosis. Some patients recovered fully, and have had their internal fixations removed. Because we did not get the information of all of the patients about their post-treatment, we cannot conduct a detailed description and analysis of their current situation. In the next two years, we will keep in touch with Nepal's peers, and continue to follow-up with the 27 patients.

Acknowledgments Thanks for the help of two volunteers in Nepal, their names are Vijay and Asheem Man Singh Basnyat.

Thanks to Joshua Thomas Block, who provided professional Englishlanguage editing of this article.

\section{Compliance with ethical standards}

Conflict of interest The authors declare that they have no conflict of interest.

Funding There is no funding source.

Ethical approval This article does not contain any studies with human participants or animals performed by any of the authors.

Open Access This article is distributed under the terms of the Creative Commons Attribution 4.0 International License (http:// creativecommons.org/licenses/by/4.0/), which permits unrestricted use, distribution, and reproduction in any medium, provided you give appropriate credit to the original author(s) and the source, provide a link to the Creative Commons license, and indicate if changes were made.

\section{References}

1. M7.8-34 km ESE of Lamjung, Nepal. United States Geological Survey. 25 April 2015. Retrieved 12 May 2015

2. Briefing on the $8.1 \mathrm{M}_{\mathrm{s}}$ earthquake in Nepal in April 25, 2015 China Earthquake Networks Center. 25 April 2015. Retrieved 28 April 2015

3. Incident Report of Earthquake 2015. Nepal Disaster Risk Reduction Portal. Drrportal. Gov. np. Retrieved 28 May 2015

4. Talbot M, Meunier B, Trottier V et al (2012) 1 Canadian Field Hospital in Haiti: surgical experience in earthquake relief. Can J Surg 55:271-274. doi:10.1503/cjs.001411

5. Boillot F, Herard P (2014) External fixators and sudden-onset disasters: Médecins Sans Frontières experience. Int Orthop 38:15511554. doi:10.1007/s00264-014-2344-8

6. Bar-On E, Abargel A, Peleg K et al (2013) Coping with the challenges of early disaster response: 24 years of field hospital experience after earthquakes. Disaster Med Public Health Prep 7:491498. doi:10.1017/dmp.2013.94

7. Petrazzi L, Striuli R, Polidoro L et al (2013) Causes of hospitalisation before and after the 2009 L'Aquila earthquake. Intern Med J 43:1031-1034. doi:10.1111/imj.12238

8. Merin O, Blumberg N, Raveh D et al (2012) Global responsibility in mass casualty events: the Israeli experience in Japan. Am J Disaster Med 7:61-64 
9. Bozkurt M, Ocguder A, Turktas U et al (2007) The evaluation of trauma patients in Turkish Red Crescent Field Hospital following the Pakistan earthquake in 2005. Injury 38:290-297. doi:10.1016/j. injury.2006.10.013

10. Herard P, Boillot F (2016) Quality orthopaedic care in sudden-onset disasters: suggestions from Médecins Sans Frontières-France. Int Orthop 40:435-438. doi:10.1007/s00264-015-3054-6

11. Alvarado O, Trelles M, Tayler-Smith K et al (2015) Orthopaedic surgery in natural disaster and conflict settings: how can quality care be ensured? Int Orthop 39:1901-1908. doi:10.1007/s00264-0152781-z

12. Bertol MJ, Van den Bergh R, Trelles Centurion M et al (2014) Saving life and limb: limb salvage using external fixation, a multi-centre review of orthopaedic surgical activities in Médecins Sans Frontières. Int Orthop 38:1555-1561. doi:10.1007/s00264014-2451-6

13. Jiang J, Xu H, Liu $\mathrm{H}$ et al (2010) Anaesthetic management under field conditions after the 12 May 2008 earthquake in
Wenchuan, China. Injury 41:e1-e3. doi:10.1016/j. injury.2009.07.071

14. Wang HY, Duan X, Chen Y et al (2009) Microbiologic study on the pathogens isolated from wound culture among orthopaedic patients after Wenchuan earthquake. China J Orthop\& Trauma 22:910-912

15. Liu D, Zhang F, Wang J et al (2008) Bacterial infection distribution and drug sensitivity monitoring In patients with open extremity injuries caused by Wenchuan earthquake. Chin J Trauma 24:493-495

16. Wang T, Li D, Xie Y et al (2010) The microbiological characteristics of patients with crush syndrome after the Wenchuan earthquake. Scand J Infect Dis 42:479-483. doi:10.3109 /00365541003671226

17. Ran YC, Ao XX, Liu L et al (2010) Microbiological study of pathogenic bacteria isolated from paediatric wound infections following the 2008 Wenchuan earthquake. Scand J Infect Dis 42:347350. doi:10.3109/00365540903510682

18. Chen X, Wu LJ, Zhu B et al (2013) Analysis of distribution and drug sensitivity of pathogens isolated from infected Tibetan wounded in Yushu earthquake. Chongqing Med 42:27-30 